\title{
ОЦЕНКА ЗАПЕЧАТАННОСТИ ПОЧВЕННОГО ПОКРОВА ГОРОДА ВОЛГОГРАДА
}

\author{
О. Ю. Кошелева \\ Федеральный научный центр агроэкологии РАН, Россия \\ Поступила в редакцию 5 июня 2018 г.
}

\begin{abstract}
Аннотация: В статье представлены результаты оценки запечатанности почвенного покрова в различных функциональных зонах города Волгограда. На спутниковых снимках методами автоматизированного дешифрирования выделялись 2 класса - открытые и запечатанные поверхности. Установлено, что непроницаемость почвы под жилой застройкой может варьировать от 20 до $75 \%$, а в промышленной зоне непроницаемость может достигать $80 \%$. Определено соотношение запечатанных и открытых поверхностей для различных типов жилой застройки, которое зависит от размеров зданий и степени озеленения. Самая низкая запечатанность в жилой зоне отмечается для дачных массивов - около $30 \%$. Построен график изменения запечатанности городских почв при движении от пригородной зоны к берегу Волги.
\end{abstract}

Ключевые слова: городские почвы, запечатанные почвы, непроницаемость, озелененные пространства, функциональное зонирование, автоматизированное дешифрирование, космические снимки, Волгоград.

Abstract: The article presents the results of evaluation of sealed soils in different functional zones of the Volgograd city. On satellite images using automated interpretation methods, two classes were distinguished: open and sealed surfaces. It is established that the soil imperviousness under residential development can vary from 20 to $75 \%$, and in the industrial zone, imperviousness can reach $80 \%$. The ratio of sealed and open surfaces for different types of residential development is determined, which depends on the size of the buildings and the degree of gardening. The lowest imperviousness in the residential area is noted for the country houses - about $30 \%$. A graph of the sealed soils change during the movement from the suburban zone to the bank of the Volga River is constructed.

Key words: urban soil, sealed soil, impermeability, green areas, functional zoning, automated interpretation, space images, Volgograd City.

Для экологии современных крупных городов большую актуальность имеет проблема пространственной фиксации границ антропогенно-преобразованных почвенных контуров. Задача сложная в силу ряда причин трудности однозначного выявления границ ареалов, недостаточная классификационная определенность, комбинаторика воздействий, многовариантность объектов и их временная изменчивость [2]. Поэтому все большее количество исследователей при изучении городского почвенного покрова уделяет внимание запечатанным поверхностям, как однозначно выделяемым в пределах урбанизированной территории $[7,9,13]$.

Под запечатанными, или непроницаемыми, понимаются городские территории под жилыми

() Кошелева О.Ю., 2019 зданиями, дорогами, тротуарами, складскими и производственными помещениями, а также другими строениями и коммуникациями. Как правило, в результате запечатывания практически прекращается привнос в почву свежего органического вещества, нарушается водный баланс, изменяется характер теплообмена почвы с атмосферой [8]. Уплотнение почвы в общегородских масштабах способствует тепловому островному эффекту, который увеличивает температуру города [6].

Хотя непроницаемые поверхности сами по себе не вызывают загрязнения, они, между тем, являются основным компонентом интенсивного землепользования, вызывающего загрязнение. Запечатанность не способствует естественному обеззараживанию загрязняющих веществ, так как не 
допускает их просачивание в почву. Кроме того, непроницаемые поверхности служат эффективной транспортной системой для проникновения (стока) загрязняющих веществ в водные пути. Не случайно зарубежные исследователи считают долю непроницаемой поверхности индикатором воздействия городской территории на водные ресурсы. Ими была установлена сильная корреляция между непроницаемостью водосборного бассейна и чистотой и полноводностью принимающего потока $[11,14]$. По мере увеличения площади непроницаемых поверхностей, было отмечено постепенное ухудшение состояния водного потока, а при доле запечатанной поверхности свыше $30 \%$ от площади водосбора была зафиксирована необратимая деградация принимающего водотока [14].

В пользу применения показателя запечатанности для оценки антропогенной преобразованности городских почв говорит и то, что данный показатель достаточно легко измерим с помощью данных дистанционного зондирования и геоинформационных технологий. Для количественной оценки запечатанности городских почв в качестве гипотезы принимается положение о том, что каждому типу застройки присуще специфическое соотношение застроенных и незастроенных (в том числе озелененных) пространств. Мы попытались установить соотношение запечатанных и открытых поверхностей по космическим снимкам высокого разрешения на примере города Волгограда.

\section{ОБЪЕКТ ИССЛЕДОВАНИЯ}

Город Волгоград расположен на правом берегу реки Волга в нижнем ее течении. Городские земли вытянуты вдоль реки почти на 70 км при ширине от 3 до 10 км. Эта особенность определила специфику планировочной структуры города: расположение функциональных зон в виде полос, идущих практически параллельно берегу Волги.

Зональными почвами для Волгограда являются светло-каштановые почвенные разности различного гранулометрического состава и степени солонцеватости. Они залегают обычно на равнинных поверхностях и формируются под полынно-типчаковой растительностью. В пойме Волги, которая частично заходит в пределы города на юге, представлены пойменные аллювиальные почвы, которые имеют слоистое сложение, различное количество гумуса и не засолены. Антропогенные глубоко-преобразованные почвы, включая запечатанные почвы, в пределах городской территории занимают около 50-60\% [4].

\section{МЕТОДИКА ИССЛЕДОВАНИЯ}

Классификация степени запечатанности городской поверхности по космическим снимкам среднего разрешения представляет серьезную проблему из-за большой спектральной «путаницы» между различными типами землепользования [1]. Для данного исследования применялись снимки сверхвысокого пространственного разрешения GeoEye-1 (0,5 м), размещенные в свободном доступе на портале Google Earth. Основное требование к снимкам состояло в отсутствии облачности.

Для установления степени запечатанности поверхности внутри каждого типа застройки - промышленной, многоэтажной, индивидуальной (малоэтажной) и дачной застройки - были отобраны снимки для 10 тестовых участков площадью 20 га. Каждый из 40 снимков проходил процедуру автоматизированного дешифрирования методом максимального правдоподобия (Maximum Likelihood) в программе ENVI на предмет выделения на нем всего 2-х классов: запечатанных (под зданиями, асфальто-бетонными покрытиями, дорогами и т.д.) и открытых поверхностей (в том числе и озелененных). В исследовании не учитывались водные поверхности и лесные массивы в пригородной зоне.

Метод максимального правдоподобия, который относится к контролируемой классификации изображения, предполагает формирование обучающей выборки посредством создания эталонных объектов на снимке (Region of Interest, ROI). Для оценки общей достоверности классификации используется так называемый коэффициент «каппа», к. Нулевое значение коэффициента означает нулевое соответствие, а значение 1,0 - полное соответствие между результатами классификации и эталонными данными. Обычно считают качество классификации хорошим, если $\kappa>0,75$, и неприемлемым, если $\kappa<0,40$ [5].

\section{РЕЗУЛЬТАТЫ ИССЛЕДОВАНИЯ}

Территорию Волгограда в общем можно подразделить на следующие функциональные зоны: селитебную (много- и малоэтажная квартальная застройка), агроселитебную (индивидуальная застройка с приусадебными участками), промышленную (объекты промышленного и коммунально-складского назначения), транспортную (улицы, автомобильные и железные дороги), а также рекреационную (парки, скверы, лесные массивы). Помимо функционального назначения территории, различия между ними обусловлены размерами и конфигурацией зданий, плотностью транспортной 

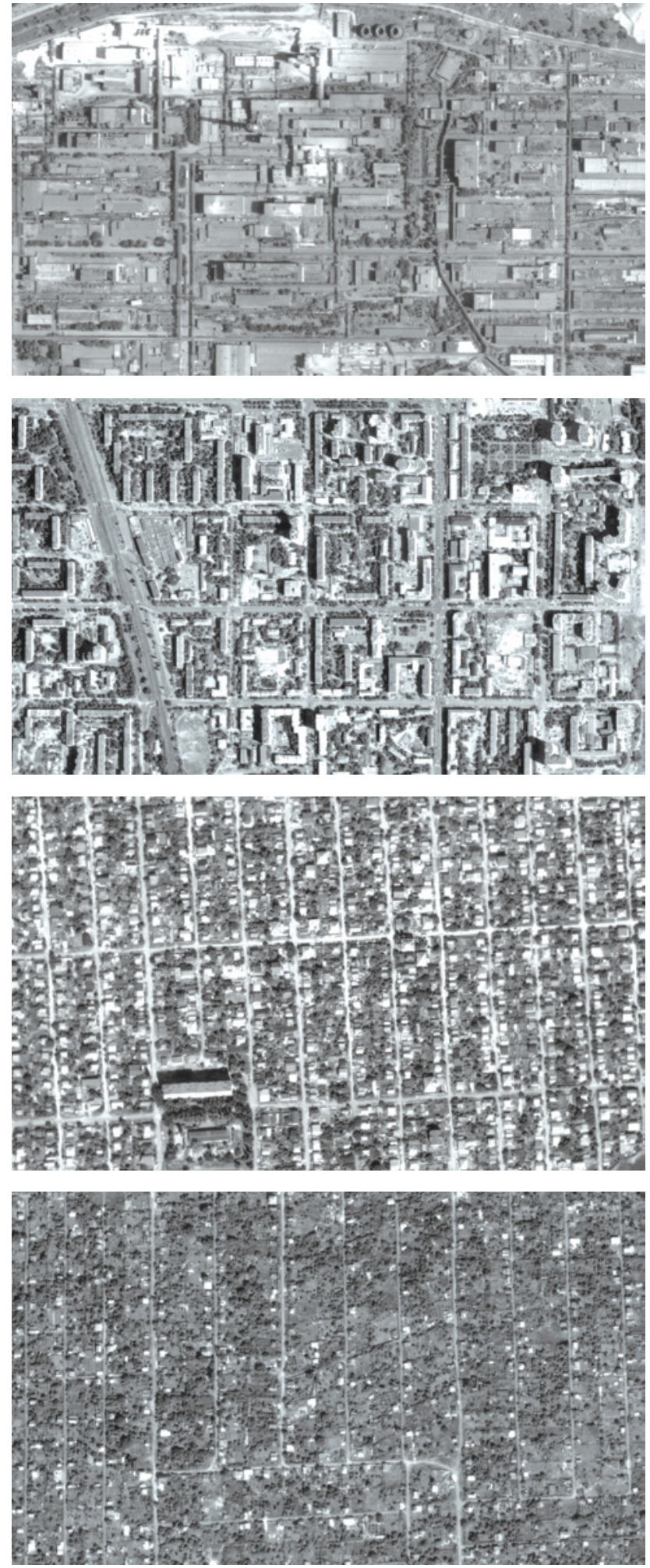
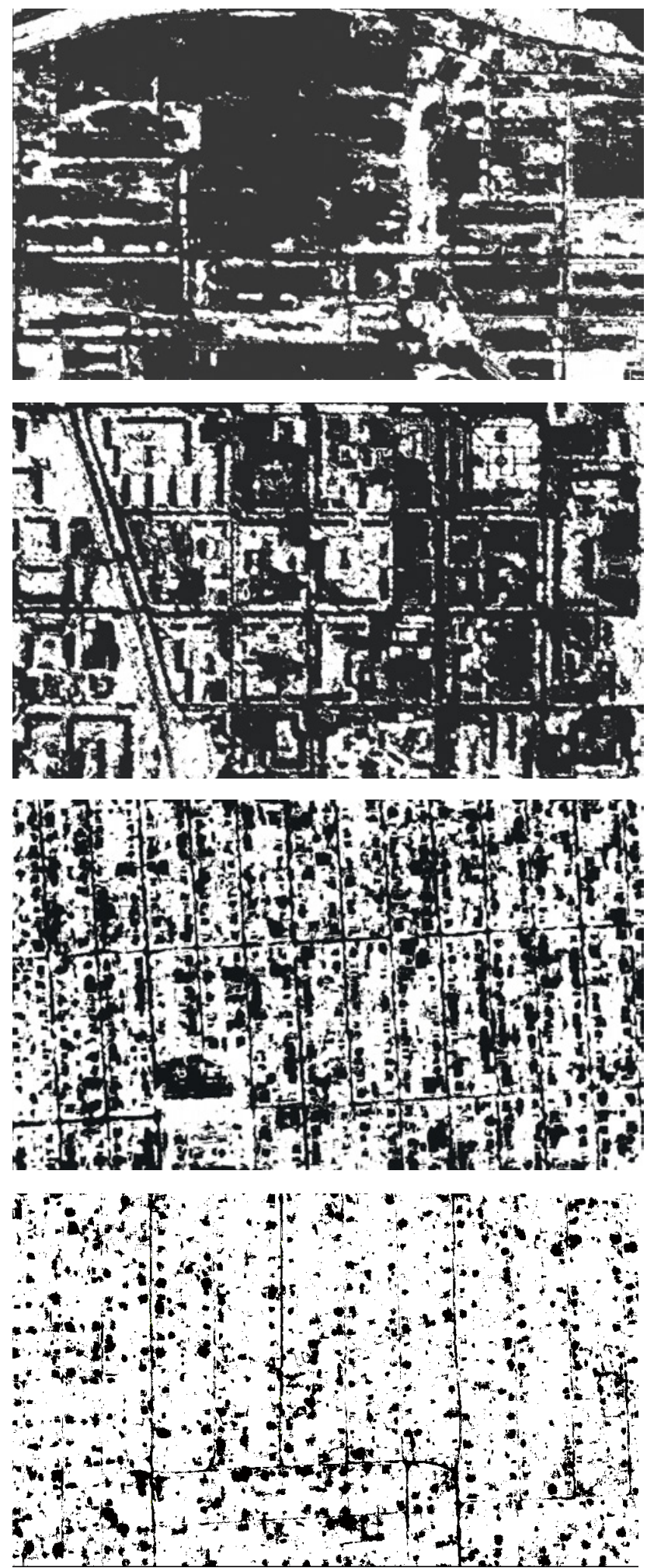

Puc. 1. Пример классификации космического снимка методом максимального правдоподобия:

A - промышленная застройка; Б - многоэтажная застройка; В - индивидуальная (малоэтажная) застройка; Г - дачная застройка

сети, площадью и характером зеленых насаждений. Таким образом, для различия территориальных единиц в городе достаточно оперировать показателями застроенности, степени озеленения и плотности автотранспортной сети [3]. Это положение легло в основу нашего исследования. Однако для работы с данными дистанционного зондирования мы объединили застройку и автотранс- 


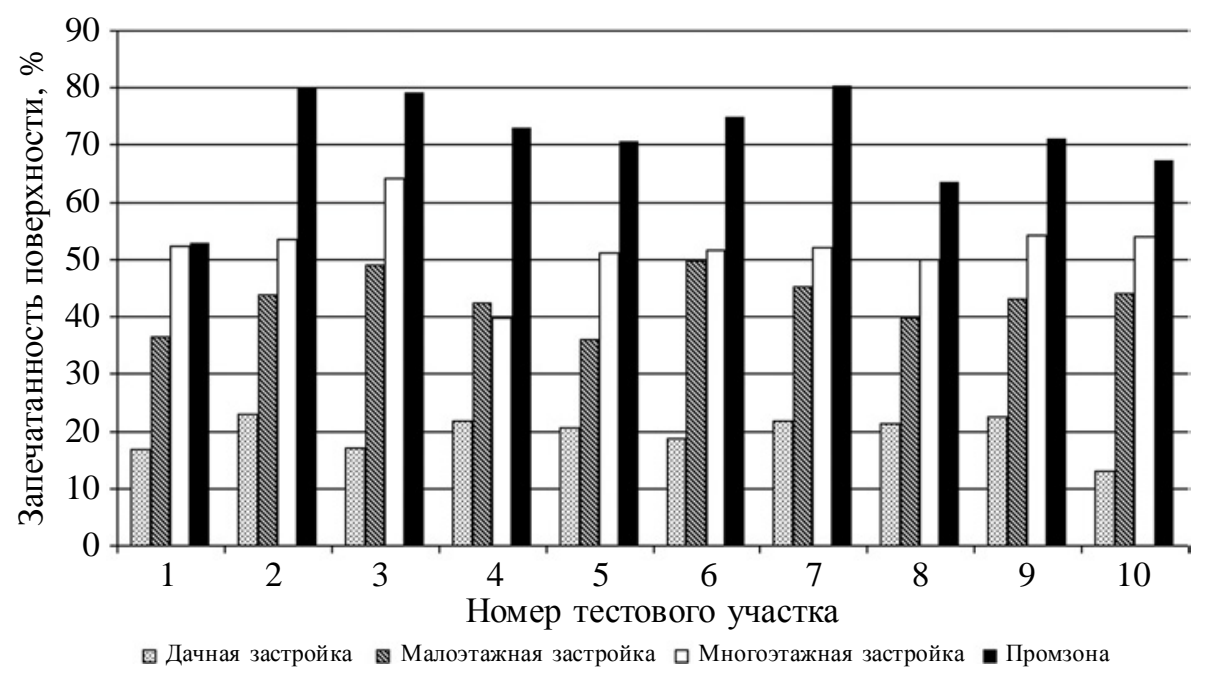

Puc. 2. Запечатанность поверхности (в \%) различных типов городской застройки Волгограда на примере тестовых участков

портную сеть в один класс - запечатанных поверхностей.

При взгляде сверху, со спутника, кроны деревьев, используемых в общегородском и внутридворовом озеленении, делают запечатанные поверхности, особенно внутри дворов и в парках, либо частично затененными, либо полностью необнаруживаемыми, что приводит к появлению скрытых форм объектов при автоматизированном дешифрировании. Именно поэтому на классифицированных космических снимках дороги и другие антропогенные объекты могут иметь прерывистую, непрямолинейную, форму. Такая ситуация создает некоторые проблемы при идентификации запечатанных поверхностей со спутниковых изображений, так как может приводить к недооценке общей запечатанности участка [12]. Однако наши исследования по сравнению результатов дешифрирования ранневесенних (когда деревья находятся в безлиственном состоянии) и летних снимков показало, что среднее соотношение запечатанных и открытых поверхностей все равно остается примерно одинаковым. Еще одним слабым местом при автоматизированных классификациях является наличие теней возле каждого объекта, особенно крупных зданий и сооружений. В силу перечисленных выше обстоятельств, мы видим (рис. 1), что с помощью автоматизированного дешифрирования можно лишь обозначить местоположение строений, но нельзя точно отрисовать их контура. Приведение таких результатов в законченный вид требует значительной ручной доработки. Вместе с тем, метод максимального правдоподобия пока- зал достаточно высокую точность. Коэффициент составил 0,79-0,88.

Наибольшая доля запечатанных поверхностей характерна для зоны промышленной застройки, которая приурочена к 1-1,5-километровой полосе, протянувшейся вдоль берега Волги. Среднее значение запечатанности территории здесь составляет 71,2\% от площади тестового участка, достигая в некоторых местах $80 \%$ (рис. 2).

Следующая функциональная зона, расположенная, как и промышленная, в виде полосы, идущей параллельно Волге, является зона много- и малоэтажной, а также общественно-деловой застройки. Здесь преобладают урбаноземы - генетически самостоятельный поверхностный слой почвы, созданный человеком в результате градостроительных работ (перемешивания, погребения или загрязнения строительно-бытовым мусором) и жизнедеятельности городского населения [10]. Эта группа почв является одной из самых обширных, она занимает около $24 \%$ территории города Волгограда [4].

За счет общегородского (парки, скверы) и внутридворового озеленения соотношение «запечатанность/открытость» на участках многоэтажной застройки составляет практически один к одному (52,3\% и 47,7 \%), с небольшим перевесом запечатанных поверхностей. На участках с малоэтажной застройкой ненамного преобладают открытые поверхности $(57,1$ \%). Иная картина на тестовых участках дачных массивов. За счет небольшой площади дачных домиков и хозяйственных построек (по сравнению с индивидуальной застройкой) и 


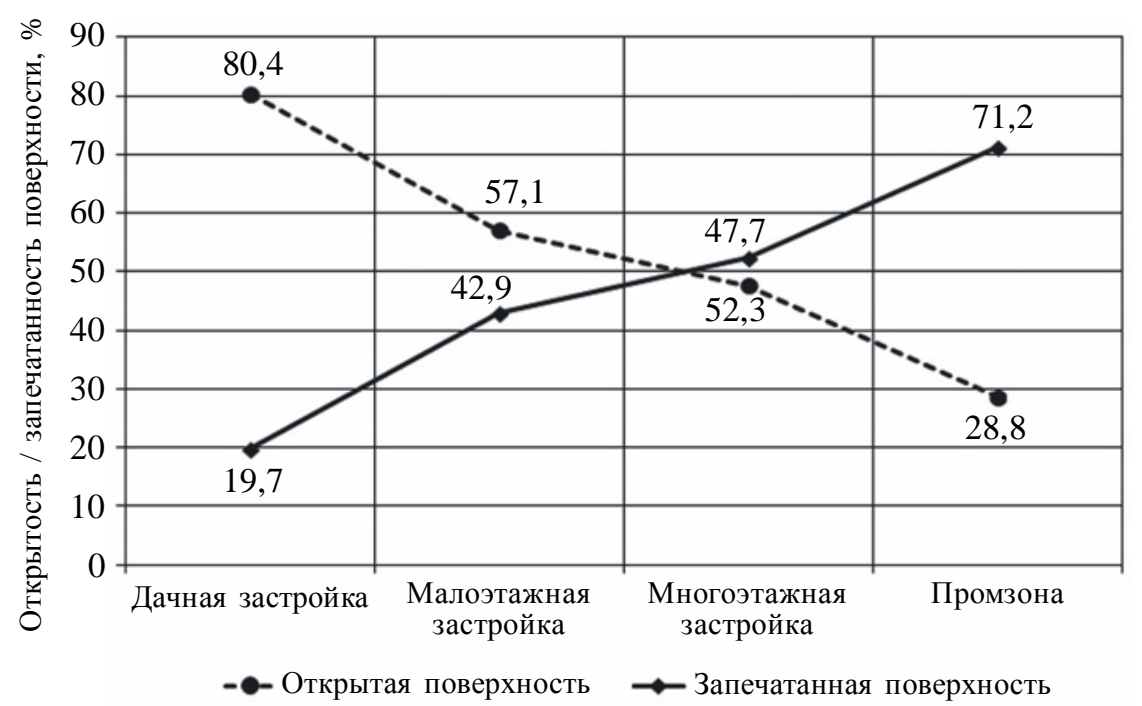

Puc. 3. Соотношение открытых и запечатанных поверхностей в различных типах городской застройки Волгограда

высокой степени озеленения здесь преобладают незапечатанные поверхности $(70,4 \%)$.

Повсеместное асфальтирование негативно сказывается на экологической обстановке в городе и, следовательно, на условиях существования человека. Возможно ли найти баланс между сплошным запечатыванием поверхности и озеленением в городах? Построенные по средним значениям запечатанности и открытости городской поверхности графики отражают изменение этих показателей по поперечному профилю города Волгограда (рис. 3). В силу планировочной структуры города, запечатанность здесь растет по мере продвижения от западных границ города к берегу Волги, от зоны дачной и малоэтажной индивидуальной застройки к промышленной зоне.

Как видно из рисунка 3 , точка равновесия находится в зоне многоэтажной застройки, практически на границе с малоэтажной застройкой, то есть в хорошо озелененных кварталах многоэтажной застройки.

При увеличении доли запечатанных поверхностей будет уменьшаться площадь земель, потенциально пригодных для озеленения, что вызовет, в свою очередь, формирование тепловых аномалий и снижение комфортности городской среды. Уменьшение средней доли запечатанных поверхностей ниже $50 \%$, на наш взгляд, уже невозможно в силу причин, обуславливающих функционирование и рост крупного промышленного центра (строительство нового жилья, прокладка автомагистралей и т.д.).
Таким образом, земли под жилой застройкой в Волгограде могут сильно различаться по степени запечатанности (от 20 до 75\%), а запечатанность поверхности в промышленной зоне может достигать $80 \%$. Результаты нашего исследования показали, что для каждого типа застройки характерно определенное соотношение запечатанных и открытых поверхностей, которое хорошо отражается на космических снимках. Причем, в целом, запечатанность городской территории растет по мере продвижения от западных границ города к берегу Волги, от зоны дачной и малоэтажной индивидуальной застройки к промышленной зоне.

Дистанционная оценка почвенного покрова Волгограда по степени запечатанности поверхности позволила определить соотношение запечатанных и открытых поверхностей в различных типах застройки. А это открывает новые направления для более детальных почвенных обследований, а также позволит в дальнейшем эффективно проводить озеленительные и другие виды работ по благоустройству и планированию городской территории. Знание доли почв и грунтов, запечатанных под асфальтом, в общей городской застройке может быть необходимым при гидрологическом моделировании, рекультивации городских почв под зеленое строительство, при реконструкции и перепланировке различных участков города.

Работа выполнена по теме Государственного задания ФНЦ агроэкологии РАН (регистрационный номер AAAA-A16-116122010038-9). 


\section{СПИСОК ЛИТЕРАТУРЫ}

1. Арбузов С. А. Разработка методики автоматизированной обработки аэро- и космических снимков для мониторинга городских территорий : автореф. дис. ... канд. техн. наук : 25.00.34 / С. А. Арбузов. - Новосибирск, 2011. - 24 с.

2. Герасимова М. И. Мелкомасштабное почвенное картографирование / М. И. Герасимова, И. П. Гаврилова, М. Д. Богданова. - Москва : Географический факультет МГУ, 2010. - 119 с.

3. Колбовский Е. Ю. Ландшафтное планирование / Е. Ю. Колбовский. - Москва : Академия, 2008. - 336 с.

4. Кулик К. Н. Почвенный покров урбанизированных территорий: идентификация и картографирование по космическим снимкам / К. Н. Кулик, А. С. Рулев, О. Ю. Кошелева // Проблемы региональной экологии. - 2015. - № 3. - С. 121-126.

5. Лабутина И. А. Дешифрирование аэрокосмических снимков / И. А. Лабутина. - Москва : Аспект Пресс, 2004. -184 c.

6. Погорелов А. В. Тепловой «портрет» города Краснодара по данным спутниковых снимков / А. В. Погорелов, Д. А. Липилин // Вестник Пермского национального исследовательского политехнического университета. Прикладная экология. Урбанистика. - 2016. № 4.1. - С. 32-45.

7. Почва. Город. Экология / под ред. Г. В. Добровольского. - Москва : Фонд За экономическую грамотность, 1997. - 320 с.

8. Почвы и техногенные поверхностные образования в городских ландшафтах: монография / Г. В. Ковалева [и др.]. - Владивосток : Дальнаука, 2012. - 159 с.

9. Прокофьева Т. В. Городские почвы запечатанные дорожными покрытиями (на примере г. Москвы) : автореф. дис. ... канд. биол. наук / Т. В. Прокофьева. Москва, 1998. - 24 с.

10. Строганова М. Н. Городские почвы: опыт изучения и систематики (на примере почв юго-западной части г. Москвы) / М. Н. Строганова, М. Г. Агаркова // Почвоведение. - 1992. - № 7. - С. 16-24.

11. Arnold Ch. L. Impervious surface coverage: the emergence of a key environmental indicator / Ch. L. Arnold, Jr. Gibbons, C. J. Gibbons // Journal of the American Planning Association. - 1996. - № 62:2. - P. 243-258.

12. Cablk M. E. Detecting and discriminating impervious cover with high-resolution IKONOS data using principal component analysis and morphological operators / M. E. Cablk, T. B. Minor // International Journal of Remote Sensing. - 2003. - № 24. - P. 4627-4645.

13. Craul Ph. J. Urban soils: applications and practices / Ph. J. Craul. - New York : John Wiley \& Sons, 1999. $377 \mathrm{p}$.

14. Schueler T. K. The Importance of imperviousness / T. K. Schueler // Watershed Protection Techniques. - 1994. - Vol. 1, No. 3. - P. 551-596.

\section{REFERENCES}

1. Arbuzov S. A. Razrabotka metodiki avtomatizirovannoy obrabotki aero- i kosmicheskikh snimkov dlya monitoringa gorodskikh territoriy : avtoref. dis. ... kand. tekhn. nauk : 25.00.34 / S. A. Arbuzov. - Novosibirsk, 2011. $24 \mathrm{~s}$.

2. Gerasimova M. I. Melkomasshtabnoye pochvennoye kartografirovaniye / M. I. Gerasimova, I. P. Gavrilova, M. D. Bogdanova. - Moskva : Geograficheskiy fakul'tet MGU, 2010. - 119 s.

3. Kolbovskiy E. YU. Landshaftnoye planirovaniye / E. YU. Kolbovskiy. - Moskva : Akademiya, 2008. - 336 s.

4. Kulik K. N. Pochvennyy pokrov urbanizirovannykh territoriy: identifikatsiya i kartografirovaniye po kosmicheskim snimkam / K. N. Kulik, A. S. Rulev, O. YU. Kosheleva // Problemy regional'noy ekologii. 2015. - № 3. - S. 121-126.

5. Labutina I. A. Deshifrirovaniye aerokosmicheskikh snimkov / I. A. Labutina. - Moskva : Aspekt Press, 2004. $184 \mathrm{~s}$.

6. Pogorelov A. V. Teplovoy «portret» goroda Krasnodara po dannym sputnikovykh snimkov / A. V. Pogorelov, D. A. Lipilin // Vestnik Permskogo natsional'nogo issledovatel'skogo politekhnicheskogo universiteta. Prikladnaya ekologiya. Urbanistika. - 2016. - № 4.1. - S. 32-45.

7. Pochva. Gorod. Ekologiya / pod red. G. V. Dobrovol'skogo. - Moskva : Fond Za ekonomicheskuyu gramotnost', 1997. $-320 \mathrm{~s}$.

8. Pochvy i tekhnogennyye poverkhnostnyye obrazovaniya $\mathrm{v}$ gorodskikh landshaftakh: monografiya / G. V. Kovaleva [i dr.]. - Vladivostok : Dal'nauka, 2012.$159 \mathrm{~s}$.

9. Prokof'yeva T. V. Gorodskiye pochvy zapechatannyye dorozhnymi pokrytiyami (na primere g. Moskvy) : avtoref. dis. ... kand. biol. nauk / T. V. Prokof'yeva. - Moskva, 1998. - $24 \mathrm{~s}$.

10. Stroganova M. N. Gorodskiye pochvy: opyt izucheniya i sistematiki (na primere pochv yugo-zapadnoy chasti g. Moskvy) / M. N. Stroganova, M. G. Agarkova // Pochvovedeniye. - 1992. - № 7. - S. 16-24.

11. Arnold Ch. L. Impervious surface coverage: the emergence of a key environmental indicator / Ch. L. Arnold, Jr. Gibbons, C. J. Gibbons // Journal of the American Planning Association. - 1996. - № 62:2. - P. 243-258.

12. Cablk M. E. Detecting and discriminating impervious cover with high-resolution IKONOS data using principal component analysis and morphological operators / M. E. Cablk, T. B. Minor // International Journal of Remote Sensing. - 2003. - № 24. - P. 4627-4645.

13. Craul Ph. J. Urban soils: applications and practices / Ph. J. Craul. - New York : John Wiley \& Sons, 1999. $377 \mathrm{p}$.

14. Schueler T. K. The Importance of imperviousness / T. K. Schueler // Watershed Protection Techniques. - 1994. - Vol. 1, No. 3. - P. 551-596. 


\section{О.Ю. Кочелева}

Кошелева Ольга Юрьевна

кандидат сельскохозяйственных наук, старший научный сотрудник лаборатории геоинформационного моделирования и картографирования агролесоландшафтов Федерального государственного бюджетного научного учреждения «Федеральный научный центр агроэкологии, комплексных мелиораций и защитного лесоразведения Российской академии наук», г. Волгоград, т. (8442) 46-25-68, E-mail: olya ber@ mail.ru
Kosheleva Ol'ga Yurievna

Candidate of Agricultural Sciences, Senior Researcher of the laboratory of geoinformation modelling and agroforest landscapes mapping of the Federal State Budgetary Scientific Institution «Federal Scientific Centre of Agroecology, Complex Melioration and Protective Afforestation of the Russian Academy of Sciences», Volgograd, tel. (8442) 46-25-68, E-mail: olya ber@ mail.ru 